\title{
Children's Password-Related Books: Efficacious, Vexatious and Incongruous
}

\author{
Karen Renaud ${ }^{1,2}$ (D) $\cdot$ Suzanne Prior ${ }^{1}$
}

Published online: 9 July 2020

(c) The Author(s) 2020

\begin{abstract}
Software is developed specifically for children and this often requires them to authenticate themselves, usually by entering a password. Password hygiene is important for children, because the principles they learn in early life will often endure across their life span. Children learn from their parents, siblings, teachers, and peers. They also learn from educational resources, such as children's books. We carried out a content analysis of a range of children's books that aims to educate children about passwords. We used directional coding, as informed by a systematic literature review of methods, such as those used in other content analysis-based studies of children's books. We examined the principles the books taught, and whether these were correct. We also analysed how the books portrayed the genders of characters, in various roles. We found that principle coverage was variable, with books sometimes teaching outdated principles. Genders were evenly represented in the books. Finally, our analysis revealed conflation of the terms "safety" and "security" in the cyber domain. We conclude the paper by justifying the adjectives we use in the title.
\end{abstract}

Keywords Password good practice principles $\cdot$ Children's books $\cdot$ Gender $\cdot$ Safety $\cdot$ Security

\section{Introduction}

The use of digital technology by children has increased dramatically in recent years (Brittan et al. 2018). Forty two percent of UK children aged 5-7 own a tablet, and 5\% own mobile phones (Ofcom 2019). It is fair to say that primary school children have never known life without technology, and also that many are increasingly using digital technology without supervision.

A range of IT systems are designed specifically for use by children. ${ }^{1}$ Many of these require them to authenticate themselves, presumably to protect the child's account from impersonators. This is warranted when one realises that children are at increased risk of falling victim to a cyber crime (Power 2011). There is an urgent need for children to be educated about cyber security (Edwards et al. 2015; Willard 2012), and for them to learn the right concepts from the outset (Renaud et al. 2019).

Karen Renaud

k.renaud@abertay.ac.uk

Abertay University, Dundee, Scotland, UK

2 Rhodes University, Grahamstown, South Africa
Lo (2001, p. 84) argues, "The best and most authentic materials by which to understand another culture are the books and stories written by authors of that culture for the participants of the culture." We thus focus on children's books, examining how they reflect the culture related to teaching children password "best practice."

Despite the growth of the Internet and the global move to reliance on online sources (Coughlan 2013), young children still enjoy reading and being read to. Ofcom (2016) reported that reading was the third most popular activity of primary school-aged children. Given the growth in online content consumption by children, it is gratifying that the children's book market is still growing (Onwuemezi 2016).

Our investigation focuses on what children can learn about passwords from children's books. In carrying out this research, we aimed to answer two research questions:

RQ1 How effectively do children's books teach password "best practice" principles?

RQ2 Do the books perpetuate, or alleviate, existing cyberrelated gender stereotypes?

\footnotetext{
${ }^{1}$ A search in December 2019, for "software for children", delivered 4.8 million results
} 
We commence, in the Children Authenticating section, by outlining the context of this investigation, and explaining the rationale behind the two research questions outlined above. Then, in the Password Hygiene Principles section, we report on a systematic literature review we carried out to gain insights into the methods used by other researchers to carry out this kind of investigation. Having used these insights to choose the best method, the Gender Representation section reports on our content analysis of children's books. The Systematic Literature Review section reflects on our findings and highlights their implications. We also discuss the limitations of our study and its ethical considerations, and conclude with the Searching and Refining section.

\section{Children Authenticating}

Designing authentication specifically for children is a neglected topic (Choong et al. 2019; Renaud 2009). Issues such as heterogeneity in ability (Tomlinson 2001), language proficiency (Loban 1963) and the ethics of usability testing with children (Hanna et al. 1997) can leave developers unsure about how to design and implement authentication for this particular target user group. Usability testing with children is constrained by strict ethical requirements (MacFarlane et al. 2003) which might put developers off innovating with this target group. The reality is that most developers choose to deploy the password.

\section{Password Hygiene Principles}

Because children are using passwords, it is important to ensure that they are learning the correct principles from the outset (National Research Council 1996; Renaud et al. 2019). Teachers and parents need guidance in educating children about the cyber domain (Karuppiah 2015; Metz 2008; Appleton 2003; Harlen 1997) and might well rely on a book to gather insights themselves.

In this paper, we analyse a range of publicly-available children's books to see which password principles were being covered and whether they were correct.

\section{Gender Representation}

The IT industry has a well-known gender bias (Wang et al. 2019), as does the field of cyber security (Bagchi-Sen et al. 2010). Peacock and Irons (2017) highlight the barriers that female cyber security professionals face and the gender inequality in recruitment, opportunities, and progression. LeClair et al. (2014) and Caldwell (2013) point out that the cyber skills gap (GOV.UK 2018) could be closed much more quickly if both genders were recruited with equal success.
Johnson Cobb (2018) refers to the female work force as an "untapped resource."

Pescosolido et al. (1997) argue that children's literature is highly sensitive to existing social forces. That being so, an important cultural aspect that the books allow us to explore is that of portrayed gender representation in the cyber field. Kelly (2018, p. 1191) argue, The gender balance of scientists featured in children's science trade books matters because it can activate stereotypes and affect students' comprehension.

McCabe et al. (2011) argue that showing a particular gender less frequently than their population proportion reduces the value attributed to that gender in the narrative's domain. Weitzman et al. (1972, p. 1128) argue that most children's books are about boys, men, and male animals, and most deal exclusively with male adventures. This is confirmed by more recent studies (Paynter 2011; Filipović 2018). Other studies have shown that exposure to gender stereotypic stories leads to children conforming to these roles (Fagot and Leinbach 1989).

We examined children's password-related books to determine whether existing gender imbalances in the cyber domain were being unwittingly reinforced, or whether genders were portrayed in a balanced way.

\section{Systematic Literature Review}

We planned to carry out a content analysis of a sample of children's books to answer our research questions. Content analysis is defined as a research technique for making replicable and valid inferences from texts (or other meaningful matter) to the contexts of their use (White and Marsh 2006, pp. 26-27). The constructs used to inform this kind of analysis can originate, according to (White and Marsh 2006), from existing theories, knowledge experts or previous research. Our study is informed by our expert knowledge

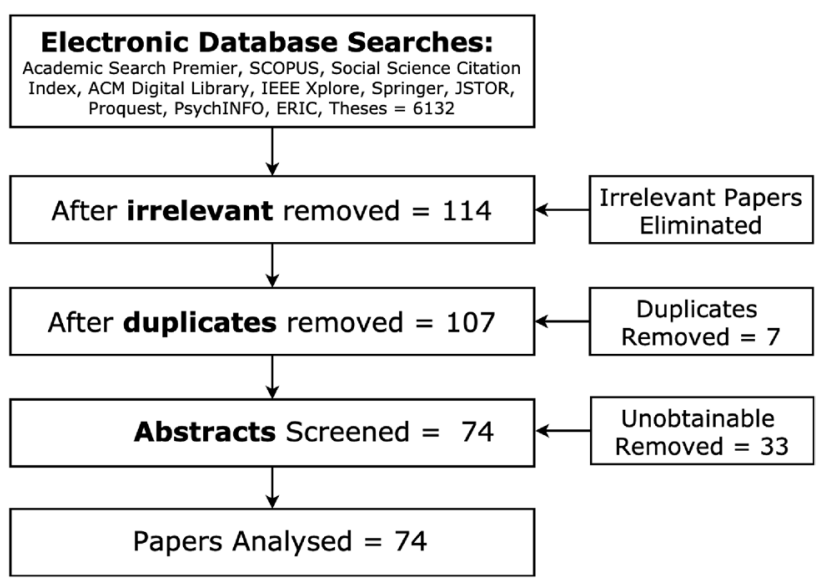

Fig. 1 Search process prisma 
Table 1 Analysis methods used by papers

\begin{tabular}{ll}
\hline Analysis method & \# Papers \\
\hline Content analysis (directional coding) (Miles and Huberman 1984) & 40 \\
Content analysis (open coding) (Miles and Huberman 1984) & 23 \\
Critical content/discourse analysis (Johnson et al. 2017; Van Dijk 2009) & 4 \\
Critical theory (Giroux 1981) & 1 \\
Overt and covert (quantitative and qualitative analysis) (Nair and Talif 2010) & 1 \\
Qualitative media analysis (Altheide and Schneider 2013) & 1 \\
Post-structural perspectives on discourse (MacNaughton 2005) and critical multicultural analysis & 1 \\
(Botelho and Rudman 2009) & 1 \\
Semiotic analysis (Manning and Cullum-Swan 1994) & 1 \\
Descriptive summary of books & 1 \\
\hline
\end{tabular}

of password best practice principles as cyber security academics.

Before proceeding with our content analysis, we reviewed methodologies used by other researchers.

\section{Searching and Refining}

We searched for peer-reviewed research papers published, in English, between 2008 and 2019, using the keywords children's books and analysis.

As recommended by (Lowry 2002), we searched Academic Search Premier, SCOPUS, Social Science Citation Index, Science Citation Index, ACM Digital Library, IEEE Xplore, Springer, JSTOR, ProQuest, PsychInfo and ERIC. We also searched for theses that were available without payment (from Ethos, DART, PQDT, EBSCO Open Dissertations and NDTLD). Only peer-reviewed papers and chapters were included, with patents excluded. Figure 1 summarises the process whereby we arrived at the 74 papers we included in our analysis.

\section{Outcome}

We analysed the papers to assess the range of methodologies used in analysing the children's books. ${ }^{2}$

If the author referred to analysing the children's books in such a way that the text revealed themes (i.e., not having any pre-defined categories to guide analysis), this was classified as "open coding." If they used pre-existing code categories, this was categorised as a "directional coding" analysis. If they specifically mentioned a different analysis approach, we included it as a separate category. The final list of methodologies is listed in Table 1.

\footnotetext{
${ }^{2}$ A full bibliography is available from Appendix A
}

\section{Using Insights}

This review informed our choice of method to use in our content analysis of children's books in the password domain. The most popular analysis method is directional coding i.e., using a pre-existing list of codes to inform the analysis. Because our first aim was to judge how well the books taught password "best practice" principles, this seemed the best methodology for our analysis, too: using a list of "best practice" principles as the pre-existing coding sheet. This could help us to determine: (a) whether each principle was covered, and (b) whether the advice was correct.

Our second aim was to examine the gender balance in the books. For this purpose, we recorded the gender of all the portrayed humans in the pictures in the books and their roles within the story. We also categorised the names used in the narrative to reveal gender balance. We coded these using the strategy described by (McCabe et al. 2011).

\section{Password Best Practice in Children's Books}

To answer RQ1, we needed a baseline to compare grounded "best practice" principles to those presented in the books. To this end, we derived an ontology of password "best practice" from advice published by standards bodies such as NIST and the NCSC in the UK (Prior and Renaud 2020). This gave us a benchmark to support analysis of the advice presented in the children's books. Figure 2 depicts the final best practice ontology. These principles were used as codes to inform our directional coding.

To answer RQ2, we carried out a frequency analysis of the pictures and character names in the books to quantify gender representation in the books.

\section{Searching for Books}

A range of talented authors publish IT-related children's books. For example, the publisher DK publishes Computer 
Fig. 2 Ontology of best practice password principles (amended from Prior and Renaud (2020))

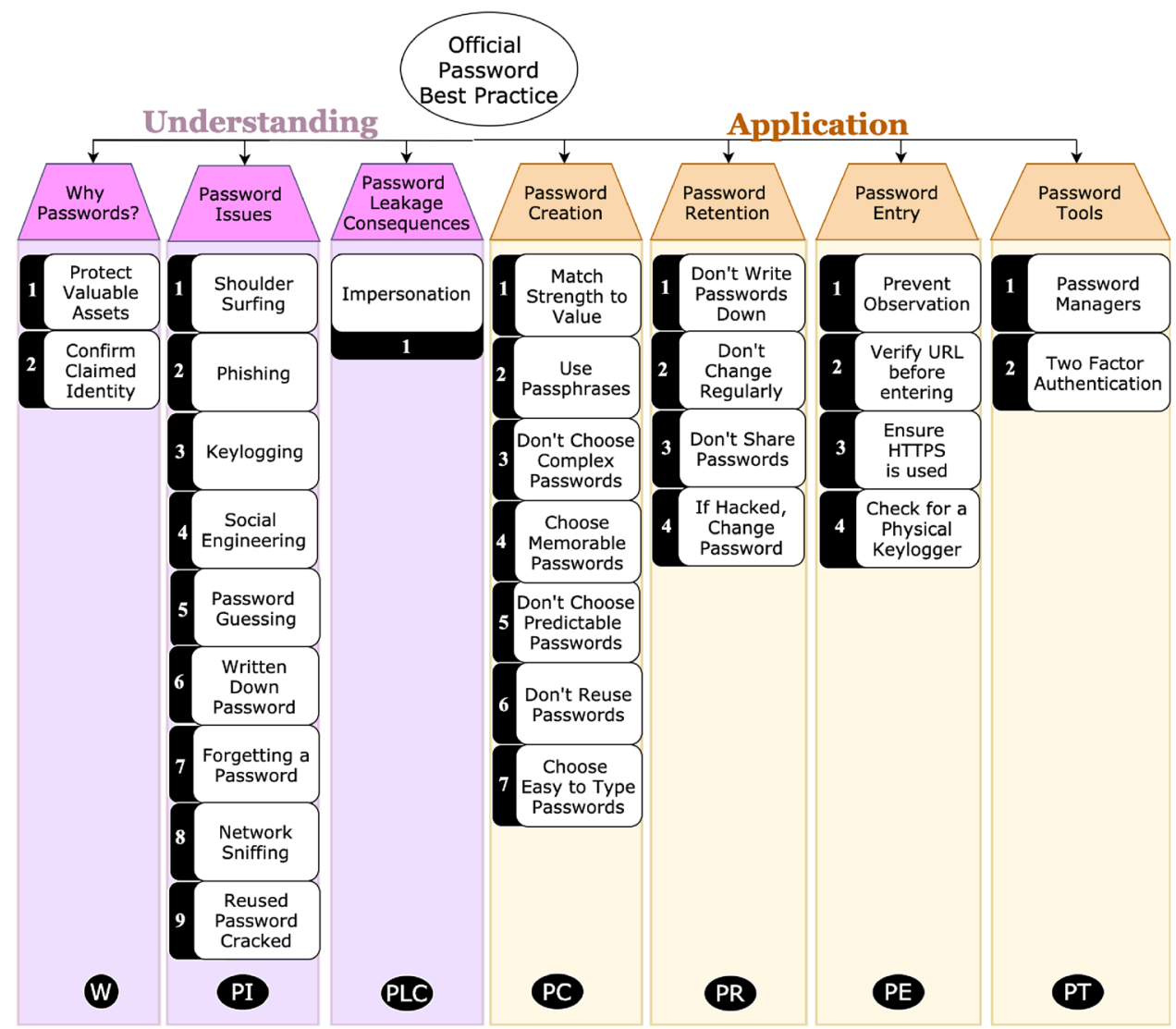

Coding for Kids: A Unique Step-by-Step Visual Guide, from Binary Code to Building Games. A Google search on https://www.amazon.co.uk in December 2019 for cyber bullying returned 98 books. These are important topics, but these books do not specifically cover password principles.

We thus searched for education and reference books using the search term "passwords" on https://www.amazon.co.uk in December 2019. The first page displayed 16 books, 15 of which were books for recording passwords (definitely not good practice). Only one was a book to teach children about passwords, published in 2018. There were 14 pages in total. The subsequent pages did not include any relevant books.

To find more books, we visited the UK's national bookseller (Waterstones). They offered a wide range of cyber bullying and cyber safety books, but none dealt with password-related principles. We then searched for books on https://www.amazon.com, https://www.wordery.co. uk, https://www.abebooks.co.uk, https://www.ebay.co.uk, https://www.ebay.com and also at second-hand bookshops and our city's local public library. We borrowed and purchased books and downloaded Kindle books. To be included in the data analysis, the book had to mention passwords, either as a prominent part of a story or in explicit advice.
We retrieved a total of 21 books, 6 of which were discarded because, despite seeming applicable, they did not include password best practice guidance. There was no mention of passwords within (Masters 1983; Palin 2017; Orr 2008; AlQasem 2015), and some books were for adults (Sherman 2003; Ribble 2009). A total of 15 books (fiction $\mathrm{n}=4$, non-fiction $\mathrm{n}=11$ ) remained to support analysis. We commenced searching in November 2018 and concluded in November 2019. Table 2 lists the books we analysed.

\section{Method}

Phase 1: Password Best Practice Coverage we carried out directional coding (Miles and Huberman 1984), as informed by Dimac's coding of IT books (Dimac 2008). Each book is a single unit of analysis. We examined the book to reveal which principles were covered. For each principle that appeared, we considered whether it was conveyed correctly.

Phase 2: Picture Coding We counted each character's name in the book as being (1) a masculine name or pronoun (m) (he/e.g. James), (2) a feminine name or pronoun (f) (she/e.g. Charlotte), (3) gender neutral (they), or (4) ambiguous (e.g. Jo or Terry). When in doubt, we used the 
Table 2 Analysed children's books (extended from the table in Prior and Renaud (2020))
Fig. 3 Children's Books' Coverage of Official Guidelines (Acronyms on $\mathrm{x}$ axis from Fig. 2) Prior and Renaud (2020)
Book Title \& Author

Year Fiction/ Age Range Non-

fiction

Internet safety by Sherman (2003)

$2003 \mathrm{NF}$

Internet safety—kids' guide by Roddel (2006)

Keep your passwords secret by Miller (2014)

$2006 \mathrm{NF}$

$10+$

Passwords and security by Minton (2014)

Lizzy's Triumph over cyber-bullying by Du Thaler (2015)

Understanding computer safety by Mason (2015)

Usbourne staying safe online by Stowell (2016)

The Magic Zablet by Gosnold (2016)

Lucy's family launches into the cyber world by Du Thaler (2017)

Dot.Common Sense by Hubbard (2018a)

A focus on... online safety by Cavell-Clarke and Welch (2018)

Passwords are secret by Ardely (2018)

Staying safe online by Cavell-Clarke and Welch (2018)

Safety and security by Hubbard (2018b)

$2014 \mathrm{NF}$

Pre-teens

2014 NF

$12-17$

$2015 \quad F$

$8-12$

$2015 \mathrm{NF}$

$8-12$

2016 NF

$8-11$

2016 F

$11+$

$2017 \quad \mathrm{~F}$

$9+$

2018 NF 6-8

2018 NF $\quad 5-8$

2018 NF $\quad 6-9$

2018 NF $\quad 6-9$

2018 NF 7-11

Sharing passwords featuring peggy the parrot by Stanley and Stead (2019)

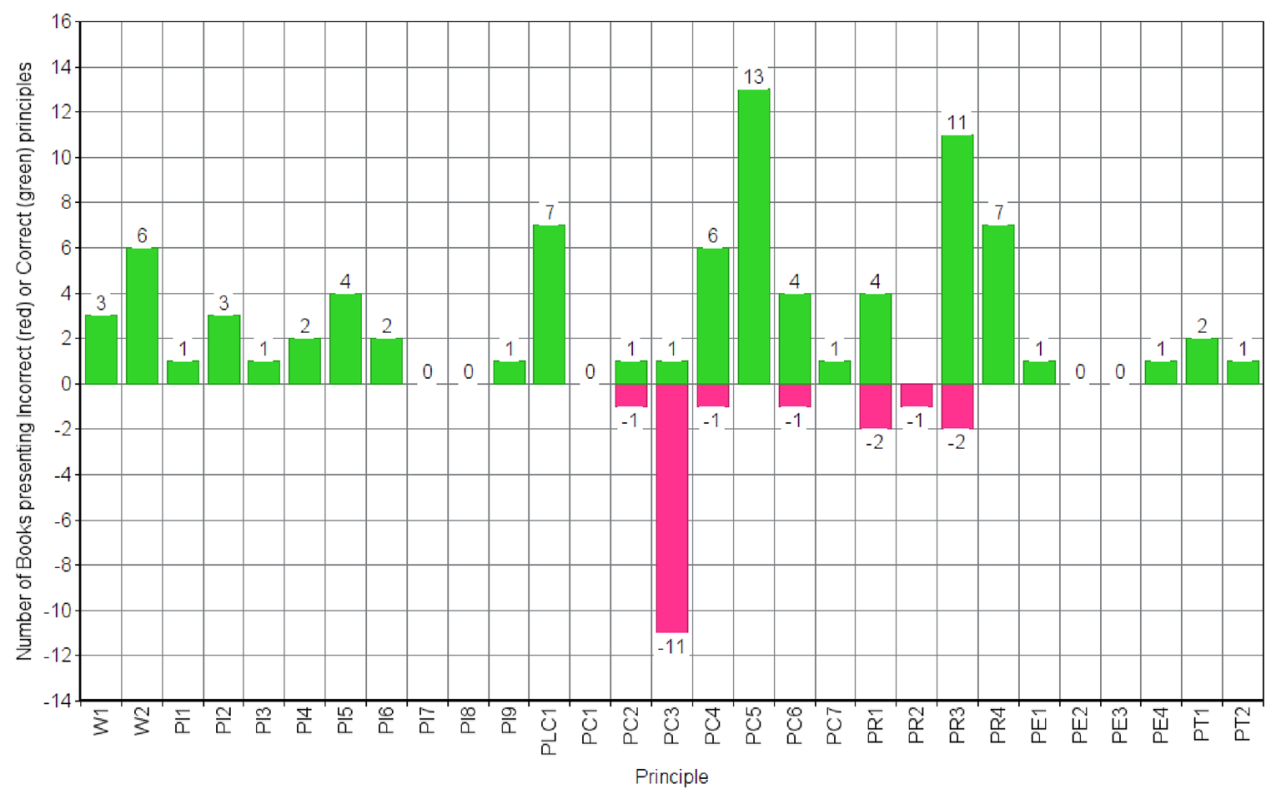

Gender Checker website, ${ }^{3}$ or the picture accompanying the use of the name, to classify names as either male or female. We then applied the same schema to the pictures, tallying the gender of (a) children (ox/o), (b) adults $\left(\sigma^{x /} / \% /\right.$ ? or (c) hackers $\left(\sigma^{x / o / ?)}\right.$. ( $\sigma^{7}=$ male; $q=$ female; ? = ambiguous) The gender classification was judged independently by the two authors, who then met to agree on categorisations. Where they could not agree, a third independent researcher was consulted to help the coders to agree on a

\footnotetext{
${ }^{3}$ https://genderchecker.com/pages/search-engine
}

final gender classification. In rare cases where we could not decide, we classified the character as ambiguous.

\section{Findings}

\section{Password Best Practice Coverage}

Figure 3 shows the coverage and correctness of the "best practice" principles conveyed in the children's books.

Figure 4 shows the "best practice"coverage by each book, in total, and incorrectly. The minimum number of principles covered by each book was 4 , and the maximum was 17 . The 
Fig. 4 Number of best practice principles covered (blue top line $=$ total, red bottom line $=$ incorrect) (Color figure online)

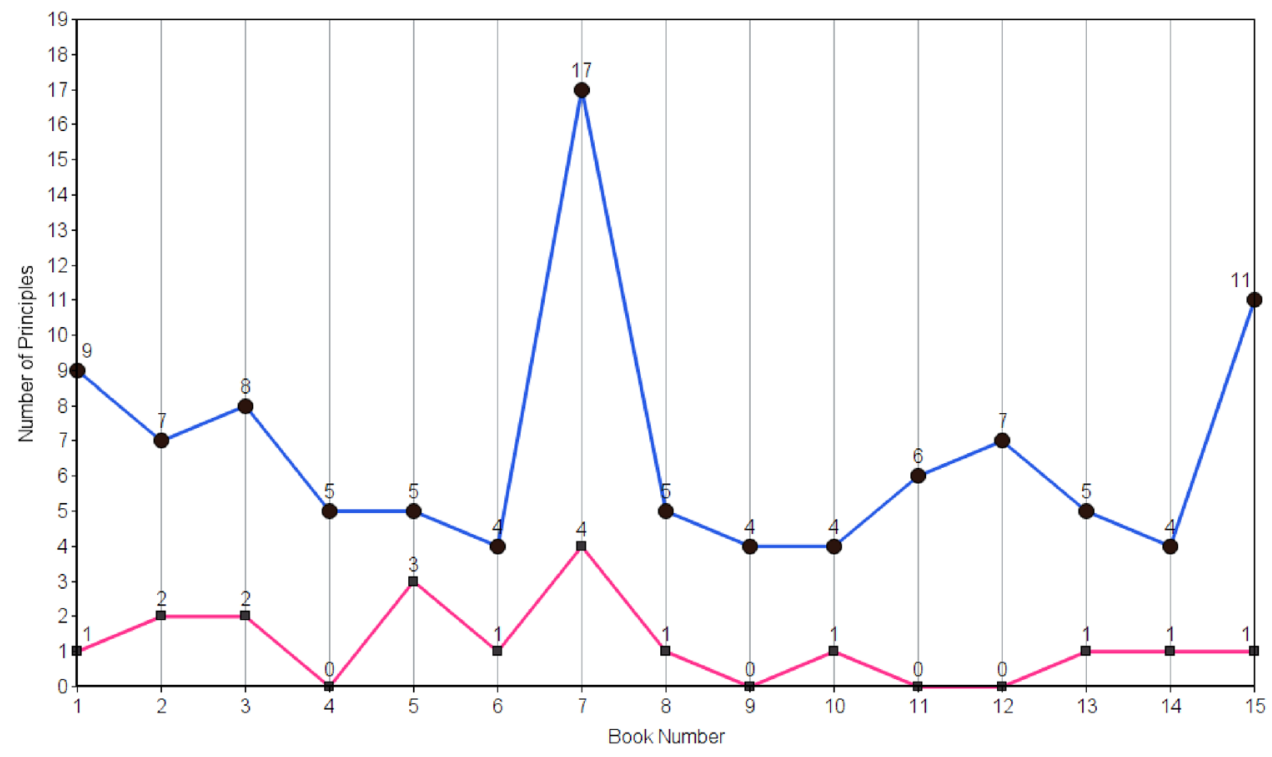

mean was 6.73 and the median 5. The standard deviation was 3.51 . The one outlier was 17 principles covered by a single book.

\section{Picture Coding}

Table 3 presents the tallies related to gender appearances in the children's books.

\section{Discussion and Reflection}

\section{RQ1: How Effectively Do Children's Books Teach Password "Best Practice" Principles?}

Our investigation revealed that password best practice principle, as shown in Fig. 2, coverage is variable. Some books covered only 4 principles, while others covered 17 . None covered all advice, which is understandable given that these are children's books. More concerningly, eleven mingled correct and incorrect advice. This is unsurprising. The sources (Prior and Renaud 2020) consulted to derive the best practice ontology (Grassi et al. 2017, Centre for the Protection of National Infrastructure 2015; UK Government 2020) were published in 2017, and most of the books were published before then. Yet even the books published after 2017 contained incorrect advice. Only one recommended passphrases (PC2), as advised by all the latest standards documents. The most common piece of incorrect advice recommended password complexity (PC3). Moreover, not a single book suggests matching the strength of the password to the value of what is being protected (PC1). It is unreasonable to expect anyone to use the strongest possible password for all their accounts. In the physical world, this principle is taken for granted. The bank's vault uses a far stronger lock than a padlock which is attached to a suitcase. Yet in the virtual world, the advice is to use strong passwords for all accounts, and a number of books also advise not writing down the passwords. We know enough from studies into adult behaviour (Adams and Sasse 1999) to conclude that children are unlikely to be able to follow both of these pieces of advice at the same time.

\section{RQ2: Do the Books Perpetuate, or Alleviate, Existing Cyber-Related Gender Stereotypes?}

The table reveals that gender representation is fairly even handed, with a slight preference for females. We also noticed that the illustrators were predominantly female, but we do not know whether this is why the representation of gender is so well-balanced. Hackers are predominantly male in the books, but this is actually representative of the actual population of cyber hackers (Newcomb 2016). With only six appearances across all books, this does not seem concerning or significant.

We can thus conclude that the books alleviate existing gender stereotypes, in terms of children of both genders using and learning about computers.

\section{Conflation of Safety and Security}

The observant reader will have noticed that many of the books we analysed include the word "safety" in their title. Even so, they did include advice about password principles, so we included them in our analysis. It turns out that this was a portent of a tendency in many of the books to conflate the terms "safety" and "security" in the cyber domain. 


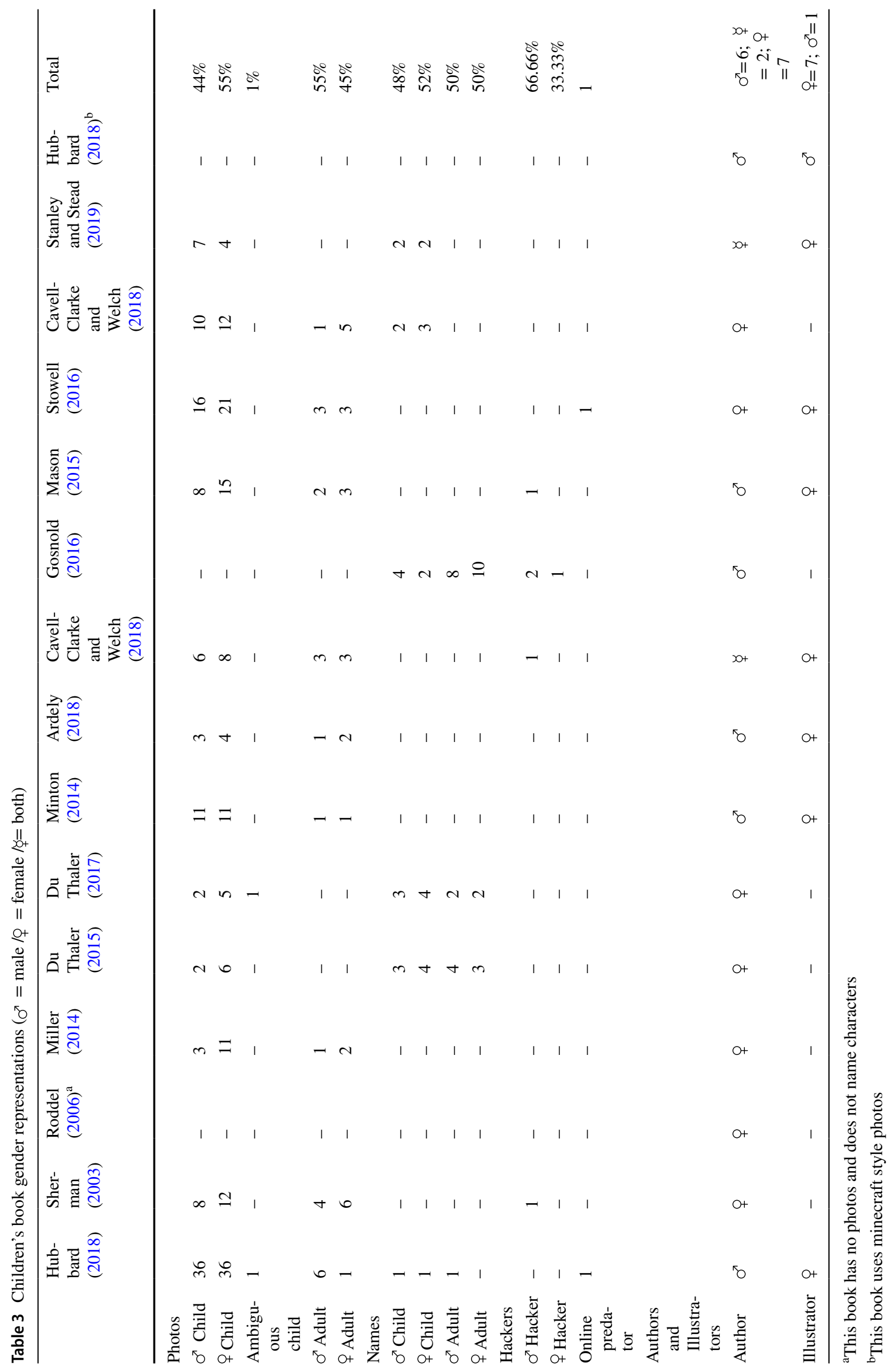


Some examples demonstrate conflation or interchangeable usage. The book titled Staying Safe Online (CavellClarke and Welch 2018) concludes with a two page spread titled Top Tips for Online Safety. This includes (1) thinking before you post, (2) being careful who you chat to, and (3) being careful about what is shared online. These are all arguably safety related. Yet the final piece of advice is: Always remember to keep your passwords private and make them difficult for other people to guess [p. 23]. Mason (2015) includes the same advice, also under a safety umbrella. This is related to cyber security and cyber safety. Keeping a strong password private will not guarantee a child's safety, either online or offline. The password is essentially a mechanism designed to protect information, not children's safety.

The book titled Keep Your Passwords Secret (Miller 2014) includes the following advice: "It is not safe to share your password" [p. 10]. The book titled Passwords and Security (Minton 2014) says: "Your password keeps your online account safe" [p. 4]. Safety is the wrong word to use in both these examples as these are security principles.

Addressing cyber security under a cyber/online "safety" umbrella is suboptimal and could lead to confusion. Cyber security exists as a separate discipline and ought to be distinguished from cyber safety. The differences are nuanced and require an independent study, so this will be the topic of future research.

\section{Implications and Ameliorations}

\section{Best Practice}

An understanding of password "best practice" and cultural usage represented in children's books is important. Our review suggests that the books, at least the ones we were able to find, are not doing a great job of conveying password best practice principles correctly.

Given the durability of paper-based books, and the dynamic nature of the cyber field, we can only conclude that such books could well do more harm than good to any child who stumbles upon them. Even so, the fact that we were able to find relatively few books in a whole year of searching suggests that they are probably not going to have a huge impact. If we can make sure that the right advice gets to schools and parents, it is possible to counteract incorrect advice appearing in books and elsewhere.

It might seem that online sources are in a better position to provide up-to-date education, but we found that online sources, too, were delivering incorrect advice because they, too, were not kept up to date (Prior and Renaud 2020).

In a fast-moving domain, such as the cyber domain, it would be better for subject experts to produce best practice guidelines on a regular basis, perhaps annually, as a resource for teachers and parents (Von Solms and Von Solms
2015). The cyber world changes all the time, and the advice needs to be kept up to date too. Similar to the "foreign travel advice" issued by the UK government, cyber advice should be a dynamic resource, being kept up to date as the landscape changes and new standards replace outdated ones. A mechanism for supplying such advice to parents and teachers is urgently required.

As a first step towards formulating an educational approach, we developed three age-appropriate password "best practice" ontologies: for 4-5, 6-7 and 8-9 year olds (Prior and Renaud 2020). As a next step, we will work on lesson plans that teachers and parents could use to convey these principles to their charges. These need to be taught based on the children's existing comprehension of the domain, as recommended by (Edwards et al. 2018). Edwards et al. cite (Vygotsky 1987) to highlight the fact that any such teaching should be based on concrete principles, merging everyday and scientific concepts. This will be the topic of future research.

\section{Gender Stereotyping}

The implications of the findings are that young girls will also be able to imagine themselves using and learning about computers. Moreover, young boys will see that girls, too, can be equally active in the computer domain. This is a very positive effect of the way these books have been written and illustrated.

\section{Cyber Safety and Cyber Security Conflation}

The terms "safety" and "security" are often used either interchangeably or as a word pair (Hou et al. 2015; Jansen et al. 2016). Choong et al. (2019) found evidence that children were conflating safety and security, so this issue is unlikely to be limited to usage within children's books.

Even so, it is important to realise that cyber safety and cyber security have different meanings. The DigitalGuardian $^{4}$ defines cyber security as the body of technologies, processes, and practices designed to protect networks, devices, programs, and data from attack, damage, or unauthorized access. Cyber security may also be referred to as information technology security. The final phrase is important; cyber security is related to the confidentiality, integrity and availability of digitally stored information (Von Solms and Van Niekerk 2013).

It is much harder to find a good definition of cyber safety, as pointed out by (Thierer 2014). He argues that cyber safety can best be understood by relating the risks it covers: including "objectionable content," "predation," "cyberbullying"

\footnotetext{
${ }^{4}$ https://digitalguardian.com/blog/what-cyber-security
} 
or "harassment." This makes it clear that cyber safety is not equivalent to cyber security, nor can a child's online safety be preserved solely by means of a password.

Consider Jona, a child who has a social networking account. Jona knows how to use a strong password and does so. Jona proceeds to befriend other children online. One day a friend request arrives from a friend of one of Jona's friends. Jona is reassured by the fact that their best friend, Sam, is this person's friend and accepts the friend request. Jona has unwittingly been drawn into a grooming network. The new "friend" invites Jona to meet his other friends at a local park for a football game. Sam is also going, so Jona's parents permit Jona to accompany Sam. Having a strong password has not kept Jona safe. It might well prevent an online predator from impersonating Jona to groom other children. However, even without access to Jona's account, the groomer in this scenario is still able to pursue his criminal activities.

Having a strong password is thus necessary but not sufficient, a subtle distinction that might not necessarily be appreciated by care givers wanting to keep their charges safe, both on- and off-line. We did not find evidence that the books were helping their readers understand this distinction.

There is another concern, in addition to the fact that parents, educators and care givers could put misplaced faith in passwords to keep their children safe online. Children become aware of being kept safe at a young age as they are strapped into their car seats, or have their hands held when they cross the road. They are told that this is necessary to keep them from being hurt. Children believe that safety is the absence of harm or danger (Collins 2001). It is not impossible for the safety concept to become infused with the dread of being hurt or injured (Cantor and Omdahl 1999).

Children hearing the terms conflated could possibly start becoming worried about passwords and other cyber security principles instead of being reassured by the protection their deployment provides.

We should help adults, educators, and caregivers to understand the nuances of these concepts. If everyone is clear about the concept meanings, they will be able to communicate these to children more effectively.

\section{Limitations}

We spent a year gathering books to support analysis. The number we found was paltry, which suggests that this is not a popular topic. Yet our analysis of this small sample delivered insights into the kinds of advice being provided by children's password-related books, and highlighted the downsides of a paper-based resource in giving advice in such a fast-moving and dynamic field.

\section{Ethics}

No children participated in this research. This project did not require review by an Ethical Review Panel because no human subjects were involved. We reviewed published research literature and children's books that were publicly available.

\section{Conclusion}

We analysed a range of password-related children's books to determine what principles children were likely to learn from them, and what norms they communicated, in terms of gender balance. Our analysis also revealed a tendency for the books to conflate the key concepts of safety and security.

To return to the adjectives we used to describe children's books in the title: we will now argue that the books are efficacious, vexatious and incongruous:

(1) When considering the way gender is being portrayed, we conclude that the books are efficacious, and have the ability to create desirable perceptions about gender balance in IT and cyber security.

(2) When considering the way safety and security are being conflated, we conclude that the books are vexatious. This highlights the urgent need to educate adults about the differences between safety and security, so that they can use these terms correctly when interacting with children.

(3) In terms of the best practice principles, we have shown that books are inefficacious. Paper-based books are an inappropriate mechanism to educate educators and parents about password best practice principles because they do not align with correct principles (i.e., they are incongruous).

In conclusion, this study highlights the fact that rather than relying on traditional sources to educate our children, the cyber field needs a more dynamic approach that can adapt to changing needs and emerging standards. Our children deserve correct and timely cyber security education, and we can meet this need, but we cannot do so using 20th century methods.

Open Access This article is licensed under a Creative Commons Attribution 4.0 International License, which permits use, sharing, adaptation, distribution and reproduction in any medium or format, as long as you give appropriate credit to the original author(s) and the source, provide a link to the Creative Commons licence, and indicate if changes were made. The images or other third party material in this article are included in the article's Creative Commons licence, unless indicated otherwise in a credit line to the material. If material is not included in the article's Creative Commons licence and your intended use is not permitted by statutory regulation or exceeds the permitted use, you will need to obtain permission directly from the copyright holder. To view a copy of this licence, visit http://creativecommons.org/licenses/by/4.0/. 


\section{Appendix A: Systematic Literature Review Papers}

Adams, M., Walker, C., \& O'Connell, P. (2011). Invisible or involved fathers? A content analysis of representations of parenting in young children's picture books in the UK. Sex Roles, 65(3-4), 259-270.

Adam, H., Barratt-Pugh, C., \& Haig, Y. (2019). "Portray cultures other than ours": How children's literature is being used to support the diversity goals of the Australian Early Years Learning Framework. The Australian Educational Researcher, 46(3), 1-15.

Anderson, C.G. (2013). Girls, STEM, and Children's Books: A Review of the Literature Concerning Girls' Interest, Motivation and Ability in STEM, Complemented by a Mixed Methods Content Analysis of Award Winning Informational Children's Books (Doctoral Dissertation).

Anderson, A.M. (2011). Power Disparities and the Structure of Childrearing: A Content Analysis of Bestselling Children's Books. Thesis, Georgia State University.

Azano, A.P., Tackett, M., \& Sigmon, M. (2017). Understanding the puzzle behind the pictures: A content analysis of children's picture books about autism. AERA Open, 3(2), 1-12.

Badot, O., Bree, J., Damay, C., Guichard, N., Lemoine, J.F., \& Poulain, M. (2016). The representation of shopping in children's books. International Journal of Retail \& Distribution Management, 44(10), 976-995.

Beaumont, E.S., Mudd, P., Turner, I.J., \& Barnes, K. (2017). Cetacean frustration: the representation of whales and dolphins in picture books for young children. Early Childhood Education Journal, 45(4), 545-551.

Beckett, A., Nick, E., Sam B., \& Sonali, S. (2010). 'Away with the fairies?' Disability within primary-age children's literature, Disability \& Society, 25(3), 373-386. https://doi.org/10.1080/09687591003701355.

Braden, E.G., \& Rodriguez, S.C. (2016). Beyond mirrors and windows: A critical content analysis of Latinx Children's Books. Journal of Language and Literacy Education, 12(2), 56-83.

Carroll, S.M., \& Rosa, K.C. (2016). Role and image of nursing in children's literature: A qualitative media analysis. Journal of Pediatric Nursing, 31(2), 141-151.

Colston, N., \& Thomas, J. (2019). Climate change skeptics teach climate literacy? A critical discourse analysis of children's books. Journal of Science Communication, 18(4), A02.

Crisp, T., Gardner, R.P., \& Almeida, M. (2018). The All-Heterosexual World of Children's Nonfiction: A critical content analysis of LGBTQ identities in Orbis Pictus Award Books, 1990-2017. Children's Literature in Education, 49(3), 246-263.
Crisp, T. (2015). A content analysis of Orbis Pictus award-winning nonfiction, 1990-2014. Language Arts, 92(4), 241-255.

Jessica, D., \& Tom, R. (2012). The portrayal of older characters in popular children's picture books in the US, Journal of Children and Media, 6(3), 333-350, https://doi. org/10.1080/17482798.2011.630741.

Dedeoğlu, H., Ulusoy, M., \& Lamme, L. L. (2011). A content analysis of international children's picture books: Representation of poverty. Egitim Arastirmalari- Eurasian Journal of Educational Research, 43, 37-52.

Morteza, D., Megan, B., Douglas, M., Ananda, M., Erin, L., \& Sandra, W. (2013). Epistemologies in the Text of Children's Books: Native- and Non-Native-authored books, International Journal of Science Education, 35(13), pp.2133-2151, https://doi.org/10.1080/09500 693.2013.823675.

Dimac, L.D. (2008). The Depiction of Information Technology in Children's Picture Books. A Master's Paper for the Masters in Science, School of Information and Library Science, University of North Carolina.

Doyle, S.L. (2009). "The stories most of all": A content analysis of bestselling children's books in Britain (1964-2004). Doctoral dissertation, University of Oxford.

Erdoğan, M., Coşkun, E., \& Uşak, M. (2011). Developing children's environmental literacy through literature: An analysis of 100 basic literary works. Egitim ArastirmalariEurasian Journal of Educational Research, 42, 45-62.

Eshan, H., Xu, X., \& Cardella, M. (2016). Representations of underrepresented characters in engineering children books. In IEEE Frontiers in Education Conference (FIE) (1-5). IEEE.

Ellefsen, K.L. (2015). Content analysis of archetypal portrayal of females in picture books read in preschool classrooms. $\mathrm{PhD}$. Walden University.

Felsinger, K.Y. (2018). The Selection, Use, and Content of Picture Books about Issues of Race in Early Elementary School. Doctoral dissertation, Mills College.

Katarina, F. (2018). Gender representation in Children's Books: Case of an early childhood setting, Journal of Research in Childhood Education, 32(3), 310-325, https:// doi.org/10.1080/02568543.2018.1464086.

Fitzpatrick, J., \& Kostina-Ritchey, E. (2013). US families' adoption of Chinese daughters: A narrative analysis of family themes in children's books. Family Relations, 62(1), 58-71.

Yilmaz Genc, M.M., Akinci Cosgun, A., \& Pala, S. (2017). A Study of Mathematical Content Provided in Illustrated Children's Books. Eurasian Journal of Educational Research, 69, 159-175.

Goldman, J.A., \& Descartes, L. (2016). Food depictions in picture books for preschool children: Frequency, centrality, and affect. Appetite, 96, 203-208. 
Grow, H., Black, S., Egan, K., Taylor, T.M., Moss, K., Wadham, R., \& Prater, M.A. (2019). A Decade of Disability Depictions in Newbery Award Books. DADD Online, p. 58.

Virginia, H. (2011). Global perspectives in Caldecott Award Books: An analysis of books from the 1970s and 2000s, Childhood Education, 87(6), 430-436, https://doi. org/10.1080/00094056.2011.10523227.

Henriksen Jr, R.C., Irby, B., \& Frels, R. (2011). A text analysis of multiple heritage young children's literature. National Forum of Applied Educational Research Journal, 24(3), 1-18.

Malina, H. (2019). Children's books as cultural products: A qualitative study of cultural representation in Hmong and Non-Hmong American Books. Master's Theses. San Jose State University.

Lear, L. (2015). Personality Traits of Young Characters in Caldecott Award Winning Picture Books from Three Time Periods: 1950s, 1980s and 2000s (Doctoral dissertation, Notre Dame of Maryland University).

Huang, X., Lee, S., Hu, Y., Gao, H., \& O’Connor, M. (2014). Talking about maternal breast cancer with young children: a content analysis of text in children's books. Journal of Pediatric Psychology, 40(6), 609-621.

Kadizade, E.D., \& Sakar, C. (2019). Violence and fear in Francesca Simon's Series of Horrid Henry. Educational Research and Reviews, 14(1), 25-32.

Kelly, L.B. (2018). An analysis of award-winning science trade books for children: Who are the scientists, and what is science?. Journal of Research in Science Teaching, 55(8), pp.1188-1210.

Jinhee K., \& Su-Jeong, W. (2018). Silent voices of homelessness: content analysis of homelessness in children's picture books published in the U.S. from 1990 to 2016, Early Child Development and Care, https://doi. org/10.1080/03004430.2018.1473388.

Layne, H., \& Alemanji, A.A. (2015). "Zebra world": The promotion of imperial stereotypes in a children's book. Power and Education, 7(2), 181-195.

Lester, J.Z. (2014). Homonormativity in Children's Literature: An Intersectional Analysis of Queer-Themed Picture Books, Journal of LGBT Youth, 11(3), 244-275, https://doi.org/10.1080/19361653.2013.879465.

Joan Katrina, M-B. (2016). What The Children Are Reading: A Content Analysis Of Minority Male Characters In Preschool Children's Libraries. Electronic Theses and Dissertations. https://digitalcommons.du.edu/etd/1208.

Martín, N.M., Hageman, J.L., Montgomery, S.E., \& Rule, A.C. (2019). A Content Analysis of Thirty Children's Picture Books about Ecology. Journal of STEM Arts, Crafts, and Constructions, 4(1), 83-120.

McCabe, J., Fairchild, E., Grauerholz, L., Pescosolido, B.A., \& Tope, D. (2011). Gender in twentieth-century children's books: Patterns of disparity in titles and central characters. Gender \& Society, 25(2), 197-226.

Monoyiou, E., \& Symeonidou, S. (2016). The wonderful world of children's books? Negotiating diversity through children's literature. International Journal of Inclusive Education, 20(6), 588-603.

Muthukrishnan, R., \& Kelley, J.E. (2017). Depictions of sustainability in children's books. Environment, Development and Sustainability, 19(3), 955-970.

Julie Nurnberger-Haag (2017). A Cautionary Tale: How Children's Books (Mis)Teach Shapes, Early Education and Development, 28(4), 415-440, https://doi. org/10.1080/10409289.2016.1242993.

Ohashi, Y. (2011). Representations of Fathers, Mothers, and Parent-figures in Japanese Children's Literature: A Content Analysis. Masters Dissertation. California State University, Long Beach.

Oppliger, P.A. and Davis, A. (2016). Portrayals of bullying: a content analysis of picture books for preschoolers. Early Childhood Education Journal, 44(5), 515-526.

Parette, H.P., Blum, C., \& Luthin, K. (2015). A quantitative features analysis of recommended no-and low-cost preschool e-books. Early Childhood Education Journal, 43(1), 27-36.

Patterson, M. (2019). Children's Literature as a Vehicle for Political Socialization: An Examination of Best-Selling Picture Books 2012-2017, The Journal of Genetic Psychology, 180(4-5), 231-250, https://doi. org/10.1080/00221325.2019.1635077.

Pennell, A.E., Wollak, B., \& Koppenhaver, D.A. (2018). Respectful representations of disability in picture books. The Reading Teacher, 71(4), 411-419.

Phillips, E.C., \& Sturm, B.W. (2013). Do picture books about starting Kindergarten portray the Kindergarten experience in developmentally appropriate ways?. Early Childhood Education Journal, 41(6), 465-475.

Poling, D.A., \& Hupp, J.M. (2008). Death sentences: A content analysis of children's death literature. The Journal of Genetic Psychology, 169(2), 165-176.

Price, C.L., Ostrosky, M.M., \& Mouzourou, C. (2016). Exploring Representations of Characters with Disabilities in Library Books. Early Childhood Education Journal, 44(6), 563-572.

Rawson, C.H., \& McCool, M.A. (2014). Just like all the other humans? Analyzing images of scientists in children's trade books. School Science and Mathematics, 114(1), 10-18.

Roper, E.A., \& Clifton, A.M. (2013). The representation of physically active Girls in Children's Picture Books, Research Quarterly for Exercise and Sport, 84(2), 147-156, https://doi.org/10.1080/02701367.2013.784844 
Sahin, A. (2019). Personal and social values in Primary Grade Children's Books. Participatory Educational Research, 6(1), 1-9.

Short, T.L. (2010). The accuracy of physical science books on the Outstanding Science Trade Books list. State University of New York at Buffalo.

Rawson, C.H., \& McCool, M.A. (2014). Just like all the other humans? Analyzing images of scientists in children's trade books. School Science and Mathematics, 114(1), 10-18.

Carolina, S., Peter, S.K., Helena, H., Marta, R., \& Patricia, B. (2010). Representations of grandparents in Children's Books in Britain, Italy, Greece, Finland, and Poland, Journal of Intergenerational Relationships, 8(3), 298-316, https://doi. org/10.1080/15350770.2010.498760.

Sigalow, E., \& Fox, N.S. (2014). Perpetuating stereotypes: A study of gender, family, and religious life in Jewish children's books. Journal for the Scientific Study of Religion, 53(2), 416-431.

Tappel, A.C., Cresce, N., \& Zlotoff, B. (2018). What's the story? An analysis of children's books about atopic dermatitis. Pediatric Dermatology, 35(5), 607-610.

Timpany, C., \& Vanderschantz, N. (2013). Using a categorisation structure to understand interaction in children's books. The International Journal of the Book, 10. https://www.books andpublishing.com, ISSN 1447-9516.

Aimee, T. (2015). Bibliotherapy for Children Coping with a Loved One's Military Deployment: What do Children's Books Tell Us? Educational Specialist Dissertation. Brigham Young University.

Wee, S.J., Kura, K., \& Kim, J. (2018). Unpacking Japanese Culture in Children's Picture Books: Culturally Authentic Representation and Historical Events/Political Issues. Reading Horizons, 57(2), 4.

Wee, S.J., Park, S., \& Choi, J.S. (2015). Korean culture as portrayed in young children's picture books: The pursuit of cultural authenticity. Children's Literature in Education, 46(1), 70-87.

Williams Jr, J.A., Podeschi, C., Palmer, N., Schwadel, P., \& Meyler, D. (2012). The Human-Environment Dialog in Award-winning Children's Picture Books. Sociological Inquiry, 82(1), 145-159.

Wilson, M.B. (2009). Constructions of Childhood Found in Award-winning Children's Literature. Doctoral Dissertation, The University of Arizona.

Yakar, Y.M. (2018). The school image in children's books. Educational Research and Reviews, 13(11), 417-422.

Yakar, Y.M. (2018). Verbal Violence in Children's Books. Journal of Education and Training Studies, 6(10), 74-82.

Yilmaz, A., \& Pala, S. (2019). Sports in Children's Picture Books. Universal Journal of Educational Research, 7(3), 824-838.

\section{References}

Adams, A., \& Sasse, M. A. (1999). Users are not the enemy. Communications of the ACM, 42(12), 40-46.

AlQasem, I. (2015). Freaky rivet online safety for kids. Nabilsi: Internet Safety Kids and Families.

Altheide, D. L., \& Schneider, C. J. (2013). Qualitative media analysis (2nd ed.). Thousand Oaks: Sage Publications.

Appleton, K. (2003). How do beginning primary school teachers cope with science? Toward an understanding of science teaching practice. Research in Science Education, 33(1), 1-25.

Ardely, A. (2018). Passwords are secret. New York: PowerKids Press.

Bagchi-Sen, S., Rao, H., Upadhyaya, S., \& Chai, S. (2010). Women in cybersecurity: A study of career advancement. IT Professional, 12(1), 24-31.

Botelho, M., \& Rudman, M. (2009). Critical multicultural analysis of children's literature: Mirrors, windows, and doors. New York, NY: Routledge.

Brittan, T., Jahankhani, H., \& McCarthy, J. (2018). An examination into the effect of early education on cyber security awareness within the UK. In H. Jahankhani (Ed.), Cyber criminology (pp. 291-306). Cham: Springer.

Caldwell, T. (2013). Plugging the cyber-security skills gap. Computer Fraud \& Security, 7, 5-10.

Cantor, J., \& Omdahl, B. L. (1999). Children's acceptance of safety guidelines after exposure to televised dramas depicting accidents. Western Journal of Communication (includes Communication Reports), 63(1), 57-71.

Cavell-Clarke, S., \& Welch, T. (2018). A focus on... online safety. King's Lynn: Booklife.

Cavell-Clarke, S., \& Welch, T. (2018). Staying safe online. King's Lynn: Booklife Publishing.

Centre for the Protection of National Infrastructure: Password guidance: Simplifying your approach. Tech. rep., National Technical Authority for Information Assurance (CESG) (2015). https://asset s.publishing.service.gov.uk/government/uploads/system/uploads/ attachment_data/file/458857/Password_guidance_-_simplifyin g_your_approach.pdf. Accessed Sep 2019.

Choong, Y. Y., Theofanos, M., Renaud, K., \& Prior, S. (2019). Case study-Exploring children's password knowledge and practices. In: Usable security workshop. San Diego.

Collins, K. S. (2001). Children's perceptions of safety and exposure to violence. International Journal of Adolescence and Youth, 10(1-2), 31-49.

Coughlan, S. (2013). Young people 'prefer to read on screen'. Retrieved 25 December, 2019, from https://www.bbc.co.uk/news/education22540408

Dimac, L. D. (2008). The depiction of information technology in children's picture books. Master's thesis, School of Information and Library Science.

Du Thaler, N. (2015). Lizzy's Triumph over Cyber-bullying!: Cyber safety can be fun. Bright Zebra.

Du Thaler, N. (2017). Lucy's family launches into the cyber-world!: Cyber safety can be fun. Bright Zebra, ebook.

Edwards, S., Nolan, A., Henderson, M., Mantilla, A., Plowman, L., \& Skouteris, H. (2018). Young children's everyday concepts of the Internet: A platform for cyber-safety education in the early years. British Journal of Educational Technology, 49(1), 45-55.

Edwards, S., Skouteris, H., Nolan, A., \& Henderson, M. (2015). Young children's internet cognition. In S. Garvis \& N. Lemon (Eds.), Understanding digital technologies and young children, chap 4 (pp. 38-45). London: Routledge.

Fagot, B., \& Leinbach, M. (1989). The young child's gender schema: Environmental input, internal organization. Child Development, 60(3), 63-72. 
Filipović, K. (2018). Gender representation in children's books: Case of an early childhood setting. Journal of Research in Childhood Education, 32(3), 310-325.

Giroux, H. A. (1981). Ideology culture and the process of schooling. Philadelphia, PA: Temple University Press.

Gosnold, J. (2016). The Magic Zablet: A story about Cyber Security, for the next generation. CreateSpace Independent Publishing Platform, ebook.

GOV.UK: Cyber security skills in the UK Labour market (2018). https://www.gov.uk/government/publications/. Accessed 12 Jan 2020.

Grassi, P. A., Fenton, J. L., Newton, E. M., Perlner, R. A., Regenscheid, A. R., Burr, W. E., Richer, J. P., Lefkovitz, N. B., Danker, J. M., Choong, Y. Y., Greene, K. K., \& Theofanos, M. F. (2017). NIST Special Publication 800-63B, Digital Identity Guidelines. Tech. rep., NIST. https://pages.nist.gov/800-63-3/sp800-63b. html. Accessed Sept 2019.

Hanna, L., Risden, K., \& Alexander, K. (1997). Guidelines for usability testing with children. Interactions, 4(5), 9-14.

Harlen, W. (1997). Primary teachers' understanding in science and its impact in the classroom. Research in Science Education, 27(3), 323.

Hou, W., Komlodi, A., Lutters, W., Hercegfi, K., Preece, J. J., \& Druin, A. J. (2015). Supporting children's online identity in international communities. Behaviour \& Information Technology, 34(4), 375-391.

Hubbard, B. (2018). Dot. Common sense how to stay smart and safe online. London: Wayland.

Hubbard, B. (2018). Safety and security. London: Franklin Watts.

Jansen, J., Veenstra, S., Zuurveen, R., \& Stol, W. (2016). Guarding against online threats: Why entrepreneurs take protective measures. Behaviour \& Information Technology, 35(5), 368-379.

Johnson, H., Mathis, J., \& Short, K. G. (2017). Critical content analysis of children's and young adult literature. New York, NY: Routledge.

Johnson Cobb, M. (2018). Plugging the skills gap: The vital role that women should play in cyber-security. Computer Fraud \& Security, 1, 5-8.

Karuppiah, N. (2015). Computer habits and behaviours among young children in Singapore. Early Child Development and Care, 185(3), 393-408

Kelly, L. (2018). An analysis of award-winning science trade books for children: Who are the scientists, and what is science? Journal of Research in Science Teaching, 55(8), 1188-1210.

LeClair, J., Shih, L., \& Abraham, S. (2014). Women in STEM and cyber security fields. In: Proceedings of the conference for industry and education collaboration, (pp. 5-7). Savannah, Georgia.

Lo, D. (2001). Borrowed voices: Using literature to teach global perspectives to middle school students. The Clearing House, 75(2), $84-87$.

Loban, W. (1963). The language of elementary school children. Issue 1 of National Council of Teachers of English Research Report. Ann Arbor: University of Michigan.

Lowry, P. B. (2002). An emerging scholar's guide to the leading international information systems and business analytics research resources and publication outlets. https://papers.ssrn.com/sol3/ papers.cfm?abstract_id $=3252222$.

MacFarlane, S., Read, J., Höysniemi, J., \& Markopoulos, P. (2003). Half-day tutorial: Evaluating interactive products for and with children. In M. Rauterberg (Ed.), Interact (pp. 1027-1028). Amsterdam: IOS Press.

MacNaughton, G. (2005). Doing Foucault in early childhood studies: Applying poststructural ideas. New York, NY: Psychology Press.
Manning, P., \& Cullum-Swan, B. (1994). Narrative, content, and semiotic analysis. In G. A. Fine (Ed.), Handbook of qualitative research (pp. 463-477). New York, NY: Routledge.

Mason, P. (2015). Understanding computer safety. London: Raintree.

Masters, M. (1983). Hawkeye Collins and Amy Adams in the case of the clever computer crooks and 8 other mysteries. Minnetonka: Meadowbrook Books.

McCabe, J., Fairchild, E., Grauerholz, L., Pescosolido, B., \& Tope, D. (2011). Gender in twentieth-century children's books: Patterns of disparity in titles and central characters. Gender \& Society, 25(2), 197-226.

Metz, A. M. (2008). Teaching statistics in biology: using inquirybased learning to strengthen understanding of statistical analysis in biology laboratory courses. CBE'Life Sciences Education, 7(3), 317-326.

Miles, M., \& Huberman, A. (1984). Qualitative data analysis: A sourcebook of new methods. Newbury Park, CA: Sage.

Miller, S. (2014). Keep your passwords secret. New York: Power Kids Press.

Minton, E. (2014). Passwords and security. New York: Power Kids Press.

Nair, R., \& Talif, R. (2010). Lexical choices and the construction of gender in Malaysian children's literature. Kajian Malaysia, 28(2), 137-159.

National Research Council. (1996). National science education standards. Washington: National Academies Press.

Newcomb, A. (2016). Study reveals the age, nationality, and motivation of hackers. https://www.nbcnews.com/tech/security/study-revealsage-nationality-motivation-hackers-n647171. Accessed Jan 2020.

Ofcom: Digital Day 2016. Results from the children's diary study (2016). https://www.ofcom.org.uk/research-and-data/multi-secto r-research/general-communications/digital-day. Accessed $25 \mathrm{Apr}$ 2020.

Ofcom: Children and parents media use and attitudes 2018. Tech. rep., Ofcom, London, UK (2019). https://www.ofcom.org.uk/researchand-data/media-literacy-research/childrens/children-and-paren ts-media-use-and-attitudes-report-2018. Accessed 25 Apr 2020.

Onwuemezi, N. (2016). Children's 2016 print book market up $11.7 \%$ to date. https://www.thebookseller.com/news/children-s-book-marke t-grows-5-399736. Accessed 25 Dec 2019.

Orr, T. (2008). Privacy and hacking (cyber citizenship and cyber safety). New York: Rosen Publishing.

Palin, L. (2017). Super cybersecurity grandma: Episode 3 - privacy and identity theft. Maryland: Ebook, Jastin Enterprises.

Paynter, K. C. (2011). Gender stereotypes and representation of female characters in children's picture books. Ph.D. thesis, School of Education.

Peacock, D., \& Irons, A. (2017). Gender inequality in cybersecurity: Exploring the gender gap in opportunities and progression. International Journal of Gender, Science and Technology, 9(1), 25-44.

Pescosolido, B. A., Grauerholz, E., \& Milkie, M. A. (1997). Culture and conflict: The portrayal of Blacks in U.S. children's picture books through the mid- and late-twentieth century. American Sociological Review, 62, 443-64.

Power, R. (2011). Child identity theft. Tech. rep., Carnegie Mellon CyLab. http://www.prism-solutions.com/uploads/1/0/6/6/10666 940/carnegia_mellon_child_id_theft_report.pdf. Accessed Apr 2020.

Prior, S., \& Renaud, K. (2020). Age-appropriate password "best practice" ontologies for early educators and parents. International Journal of Child-Computer Interaction. https://doi.org/10.1016/j. ijcci.2020.100169.

Renaud, K. (2009). Web authentication using Mikon images. In: World congress on privacy, security, trust and the management of e-business, (pp. 79-88). IEEE. 
Renaud, K., Otondo, B., \& Warkentin, M. (2019). "This is the way 'I' create my passwords"... does the endowment effect deter people from changing the way they create their passwords? Computers \& Security, 82, 241-260.

Ribble, M. (2009). Raising a digital child. Hoboken: HomePage Books.

Roddel, V. (2006). Internet safety kids' guide. Morrisville: Lulu Press.

Sherman, J. (2003). Internet safety. Los Angels: Watts Library.

Stanley, D., \& Stead, S. (2019). Sharing passwords featuring peggy the parrot. Independently Published

Stowell, L. (2016). Usbourne staying safe online. London: Usbourne.

Thierer, A. (2014). What do we mean by online safety? https:// www.fosi.org/policy-research/what-do-we-mean-online-safety/. Accessed 1 Dec 2019.

Tomlinson, C. A. (2001). How to differentiate instruction in mixedability classrooms (2nd ed.). Virginia: ASCD.

UK Government: Ask users for passwords (undated). https://desig n-system.service.gov.uk/patterns/passwords/. Accessed Apr 2020

Van Dijk, T. (2009). Critical discourse studies: A sociocognitive approach. Methods of Critical Discourse Analysis, 2(1), 62-86.

Von Solms, R., \& Van Niekerk, J. (2013). From information security to cyber security. Computers \& Security, 38, 97-102.

Von Solms, R., \& Von Solms, S. (2015). Cyber safety education in developing countries. International Institute of Informatics and
Systemics. http://researchspace.csir.co.za/dspace/bitstream/handl e/10204/8226/Von\%20Solms_2015.pdf;sequence=1. Accessed 14 Dec 2019.

Vygotsky, L. S. (1987). Problems of general psychology. In R. W. Rieber \& A. Carton (Eds.), The collected works of L. S. Vygotsky (Vol. 1). New York, NY: Plenum Press.

Wang, L., Stanovsky, G., Weihs, L., \& Etzioni, O. (2019). Gender trends in computer science authorship. arXiv:1906.07883.

Weitzman, L., Eifler, D., Hokada, E., \& Ross, C. (1972). Sex-role socialization in picture books for preschool children. American Journal of Sociology, 77(6), 1125-50.

White, M. D., \& Marsh, E. E. (2006). Content analysis: A flexible methodology. Library Trends, 55(1), 22-45.

Willard, N. (2012). Cyber savvy: Embracing digital safety and civility. Thousand Oaks: Corwin Press.

Publisher's Note Springer Nature remains neutral with regard to jurisdictional claims in published maps and institutional affiliations. 